\title{
Too Many Sounds, Too Many Sensations: Shifting Bodies Towards a Viral Being
}

\author{
Vishwaveda Joshi ${ }^{1} \&$ Ira Famarin ${ }^{2}$ \\ York University, Toronto, Canada
}

\begin{abstract}
Through this article we present an experimental method that focuses on attuning our bodies to other bodies, human and more-than-human, through sound. We suggest sounded thinking as a way to think beyond the dualisms of a thinking versus feeling body, and as a form of transindividual solidarity in times of uncertainty. Methodologically, we draw from Robin Nelson's idea of going against the primacy of data and evidence-based methods to propose a collaborative practice of Sound Journaling and a Sounded Improv that implicates our sounding human bodies with other sounding bodies, human, beyond human and material, as instruments of research in an attempt to situate this practice-based research inquiry as a resonance between theory and practice as praxis (Nelson, 2015). In our analysis, sound, bodies, and movement become focal points through which we attempt to parse what sounded thinking is and how it can be taken up in the everyday.
\end{abstract}

Keywords: sounding bodies; movement; relationality; practice-as-research; sounded thinking.

1 MA Candidate, Social Anthropology and Asian Studies. Address for correspondence: Vishwaveda Joshi, Department of Anthropology, York University, 4700 Keele Street. Email: vish2805@yorku.ca

2 Bachelor of Arts, Culture and Expression Studies. 


\title{
Too many sounds, too many sensations: shifting bodies towards a viral being ${ }^{3}$
}

\begin{abstract}
Since we are focusing on COVID-19 and in the context of sound, I was thinking we should do a sound journal (perhaps 20 minutes recordings each day of our interactions with COVID-19, with others during pandemic and trace those through sounds). I have been thinking that we can amplify the sonic and let it interpellate the spatiality of our current existence by wearing headphones when we listen to each other's recordings and walking around, and as we feel and hear, how we engage with the surroundings. SB1's email to SB2, June 14, 2020, 18:57
\end{abstract}

Allows for a very heuristic and immersive practice and might lead to somewhere interesting! SB1's email to SB2, June 16, 2020, 21:51

\section{Being with COVID-19}

When events, gatherings, classes were forced to come to a halt, we found ourselves being inundated with sounds of the keyboard, the vacuum cleaner, the water boiling, the chill breeze of the wind from the bedroom. We became attuned to the sounds of home, machines, and the environment as the sound of the streets, transportation, and crowd seem to have vanished. As the virus spreads, it makes us aware of our coexistence with the inanimate, plants, organic, and inorganic. The pandemic completely altered the habits, routines and the way we listen to the surroundings and ourselves. At the same time, the present reality underscores the way we have overlooked and normalized how sounds around us, through us and within us are supposed to be.

$\mathrm{We}^{4}$ ponder about our feelings and experiences with COVID-19 and particularly, how the sound around us has drastically changed, such that we are drawn to these new sounds, to their hapticality, as we sit with the quietude of our own apartments and exchange emails. Months before the pandemic began, we were both immersed in the hum and buzz of our routines. From juggling school, work, social and personal life, our schedules revolved around our ability to stay active. That had all changed within a week. We were now self isolating, unable to see each other, unable to go out frequently in a com-

3 Our figurative use of viral draws from Jasbir Puar's theorization of the viral as porous and its ability to stretch the host. However, our theorization of viral points to our ability as human bodies to live in collision and to transgress the limits of categorizations through a thinking that permeates and penetrates.

4 This project is a collaboration in which we have co-created, co-produced and co-written our experiences in current times through sound. We want to acknowledge our privilege in being able to safely take up a project through times when the failure of the neoliberal logic is made apparent, and the marginalized populations are the most affected. 
plete change in our routines. When we started thinking about a performance, a project or a writing practice, that can help us relay our experiences and feelings of COVID-19, we asked-how does the absence of certain sounds make us feel? Do we know what our sounding and listening bodies can do? Have our bodies heard and sounded differently during COVID-19? How do we actually express what was felt? How can we develop a transindividual solidarity through sound? That further led to several discussions about devising a practice-based method that will allow us to immerse ourselves into our sound surroundings, help us make sense of our new realities, and contextualize our experiences with sound as a way of knowing and sensing through our bodies (Feld, 2015), but also as a way of knowing, sensing, and feeling through other bodies (Moten and Harney, 2013).

In what follows, we suggest we need a way to think about how the capacities of our bodies to interact with the surroundings are reorganized because of the ongoing pandemic, as well as how we can mobilize this alteration in our ways of living to bring to the surface the underlying anarchic potentialities of political affects such that we can create unmediated solidarities across systemically imposed boundaries, and state regulations which have existed before the pandemic and may continue as things settle down. We propose sounded thinking ${ }^{5}$ as a way. A sounded thinking is not just thinking with and through sound in a divergence from the visual, rather, it is a thinking against categories and regulations. It is a turning inward to our sounds, attuning with intensities of the self and other. It breaks the dualisms of the thinking and feeling body by provoking a porosity within the body and between bodies. It creates a threshold (Blackman, 2012) where the self meets the other, the material meets immaterial, the human with the viral. And most importantly, it does not assume an objective form of knowledge or what needs to be known; it gives voice to knowledges/knowings that have not yet been configured or institutionalized. By using sound journals, which are 30-40 minute recordings of our thoughts, other sounds that surround us, and reflections of what making such recordings on our phones felt like, alongside a Sounded Improv, a dance practice fabulated through sounds, we attempt to implicate our bodies in a sounded thinking as we turn to our interiorities as sources of knowledge. The practice of recording sound journals and implicating our bodies in improvised movements guided by sounds makes sound in the overall research practice an intersubjective space of performance, communication and reflection.

For us, COVID-19 came as an interruption to the way things were, yet it created new ways to attend and encounter the everyday through sound, and the ways our bodies resonate with sound. Such a focus on sound(s), brings forth a new modality of knowledge about knowing with and knowing through sounds which refutes categorizations and challenges the primacy of the writ-

$5 \quad$ We devised the term sounded thinking to suggest a thinking not simply with and through nor a thinking with just the characteristics of sound, rather, as a thinking that provokes our sounding and listening bodies to cut through the distance between bodies and transgress categories. It draws from the nature of sound, in that it is always in motion and keeps the bodies that do such thinking in motion. 
ten word in academia as generative of knowledge and, as evidence-based ways of attaining and thinking about knowledge (Nelson, 2015). Thinking with sound prompts toward more liquid, practice led ways of research creation and inquiry and as such problematizes Western academia's stringent notions about whose knowledge and what knowledge we consider knowable. The suggested method here is open, just like sounded thinking, to changes, and to questions.

As we try to articulate the felt nature of sound and explore our interiorities through the sounding and the listening body in this paper, we recognise that documentation might not be enough. Hence, we turn to our bodies and their movement to convey what we learned and what came to be known throughout the process of creating sound journals. We hope that sounded thinking as a concept reconciles alternative forms of knowing by challenging evidence-based and quantifiable forms of knowledge by turning to sensations, feelings and sounds. Our practice draws from the practice-as-research tradition that reconciles performative and practice-based approaches of research creation with fixed notions of academic research Nelson (2015: 4), and situates the practice of sound journaling and sounded improv as praxis that denotes the "possibility of thought within both 'theory' and 'practice' in an iterative process of 'doing- reflecting- reading- articulating-doing" Nelson (2015: 32). We hope that this further encourages individuals to think outside the strictures of academia and structures of method.

\section{Sounding against fixed notions of method}

Following research tradition that uses sonic practices as methodologies to destabilize the primacy of the visual, to problematize ideas of containment as well as promote more community based, socially engaged interpretations of environments through soundscapes, we use the practice of recording our thoughts, feelings and perceptions to document the transformations within and around us in the COVID-19 context. We also turn to our sounding and listening bodies in what we call a sounded improv to understand the omni-directionality of sound in a "... practical knowing-in-doing" Nelson (2015:9) manner within an intersubjective space of sonic knowing. The practice of sound journaling likewise asks what might we learn from the sonic relationality of human voices existing in the co-presence or absence of other sounds in our surroundings and, how can this practice be a way of thinking, sounding and writing ourselves out of the colonial frameworks that dictate what knowledge looks like and should be.

This inquiry points us to Steven Feld's acoustemology, which posits that the relationality of human, non-human and beyond human voices "produces [a] consciousness of modes of acoustic attending, of ways of listening for and resounding to presence" Feld (2015: 15). Such an approach accounts for the necessity of writing our findings with greater attention to and attunement 
with the body and place wrapped by sounds and allows us to conjoin performative, practice-based modes of knowing with experiment such that the documentation of our research inquiry based in practice Nelson (2015: 4) concentrates on place based space-time dynamics of sound and sounding as relational and simultaneous.

To listen to the sounding body, we recorded our thoughts, ideas, feelings and sensings that came up during self-isolation in 30- 40 minute long recordings called Sound Journals. ${ }^{6}$ They reflect the nuances and complexities of our everyday interaction with the rhythms and vibrations of sounds within and around us. This practice occurred for eight weeks through the months of June and July 2020 and was recorded on our personal mobile phones. We then listened to each other's recordings while walking in our surroundings, using our headphones to pay attention to the textures and layers of the other person's voice and the sounds that surround them. Using headphones personalized our experience as the listener, such that it created an enclosed, acoustic space and heightened our senses as listeners. Using headphones allowed us to cut the distance between two bodies and thus, increased our capacity to feel through other bodies, feel for other bodies, and to feel other bodies feeling us Moten and Harney (2013: 98) as time and space merged in the acoustic space that was created instantaneously.

To help us make sense of the knowings emerging from the relational listening and sounding in acoustic space, we introduce sonic and affective doubling to explain the ambiguous, somewhat performative often abstract yet concrete dimensions of those experiences as they point us to "... potential modes of knowing, relating, and attending to things [that] are already somehow present" Stewart (2007: 3) in these experiences and knowings "in a state of potentiality and resonance" (ibid). The acoustic space we achieved led to forms of sonic and affective doubling, as we were now sensing both time and space separately as we walked around listening to the other person's recordings and were simultaneously experiencing the merging of time and space through sound in the acoustic spaces created by the use of headphones. Our voices through the recordings doubled back on the environmental and surrounding sounds, creating an affective tonality of instability and disruption, even though the structure of the recordings was fairly concrete. Sonic doubling occurred in the experience of these recordings as sound both directly acted on our bodies and framed an acoustic experience for us during this practice. Hence, we suggest that sound in our practice affords the formation and reformation of acoustic affective spaces, creating a transindividual solidarity that cuts through bodies and distance. Such kind of solidarity is always in motion, from one body to another. The affective quality of verbal and non-verbal sound and its ability to destabilize is prominent in the sound journals and our analysis of the recordings. We set affectivities in sounds that emerge in this relational listening process in motion as analytical strategies

6 We call them Sound Journals as the reflective process of recording our experiences with and through sound merges the digital and the analogue experience. 
to propose a sounded thinking. Such a thinking is not concerned about the sonic quality or geography when sound is received. Rather, it foregrounds our daily sonic attunement to the environment (Paiva, 2018), to the bodies around us and to ourselves within. It is concerned with the thoughts, musings and provocations that result from listening in the everyday.

The affective doubling occurred in the space of continuity and alliance created in our practice of sound journaling, where we could experience the affective responses of our bodies through the voices and sounds of other bodies. In this organically generated space of alliance, our bodies, the sounds generated by them, both internal and external, and the sounds that engulf our bodies also became analytical strategies to further our understanding of what a sounded thinking can do. It opens ourselves to knowings that would otherwise be inaccessible through normative research methods by pushing us to think in relation to one another and other bodies that surround us through sounds, rhythms, vibrations. Considering sound in bodies and bodies in sound allowed us to experience sound and bodily responses as instantaneous. It further contextualizes sounds, heard and unheard, as focal points to understand how our bodies, the places we go and socio-political aspects of everyday lives co-constitute one another. Our attempt directed us to sounded and somatic forms of knowledge as we learnt to attune ourselves in both determinate and indeterminate relations. The experiences that emerged through the practice of sound journaling became rhythmic actions that were yet to be regulated or stabilized. Such an open practice provided us with ways to move beyond the human voice and noises of the human to access relational voices of more-than-human. We could tap into the affective intensities of sounding and listening bodies that assemble and articulate but are unheard, unseen, and cannot yet be sensed.

Simultaneously, this practice helped us think about the ways the body generates and uses sounds to orient itself through the unprecedented socio-political times, respond to the pandemic, police brutality, sexual violence and abuse offences, migrant crises, allowing us to challenge our understandings of what constitutes knowledge. Our findings suggest that, since bodies are always sounding and listening, they are always experiencing a reciprocation of knowledge in ways that normative academic theorizations cannot justify. The suggested method of knowing here is open, just like sounded thinking, to changes, and to questions. We use this method to turn inwards and to philosophize with what we think, feel and derive from sounds during COVID-19 and how sound can be a starting point for a thinking that is always in motion and trespasses categories, orders and the fixity of colonial frameworks. Such a thinking also considers sound as an intense affective force that is always in-between bodies, pushing for rupture, emergence and re-emergence. Such a thinking, we suggest, affords incipient desires to lurk to the surface, making them sensible. 


\section{Sound excavations}

Throughout the practice of sound journaling, lots of themes and ideas emerged. However, there was a recurrence of certain overarching concepts and ideas. As putting nearly 100 sound journals in this paper was not possible, we extrapolated the recurring themes and created a dialogue using excerpts from our sound journals. The excerpt based dialogues are dated. Under each theme in this section, we have curated a conversation for the reader and used the emergent dialogue as our starting points to understand the new recognitions that have happened in the last few months. A challenge of writing and thinking through practice-based methodologies is how to justly attend to their capacity to rupture and affect. We put the emerging thoughts and intensities of our sounding bodies in our recordings in conversation with the concept of Deep Listening (Oliveros, 2005) to integrate our bodies with sounds in a way that goes beyond telling each other our experiences. We put Oliveros' suggestion about "going below the surface of what is heard" in practice by implicating our sounding bodies in the practice of sound journaling as "a way of listening in every possible way to everything possible, to hear no matter what you are doing" (2008). We tried to listen to micro-knowledge that lurk beneath words and help us trouble assumptions of categorical thinking. At the end of each exchange presented here, we ask 'What have we come to know by un-assuming a certain form or idea of knowledge?' 'What can a sounded thinking do and what does it make apparent?'

Prior to understanding the importance of sound and sounding bodies as analytical strategies in our excerpts, and to realize the potential of sounding bodies to sound ourselves out of regulated thinking during and after the pandemic, we must understand how attuning ourselves to sounds and their affective characteristics can open us up to micro knowledges produced by relations-in-action Feld (2015:15). To do so, we put Brian Massumi, a philosopher of affect, and Kathleen Stewart, an ethnographer's understanding of affects in conversation with Pauline Oliveros' and Steven Feld's notions of deep listening and relational listening through acoustemology. We present this dialogue before our sound journal excerpts to further our understanding of the transformative potential of sound, affects and sounding and listening bodies at use here in our practice.

When reading our excerpts, we suggest the reader read through the dialogue before reading our analysis of the thinking that has happened. SB stands for sounding bodies.

[Massumi]: That's the first sense in which affect is about intensity-every affect is a doubling. The experience of a change, an affecting-being affected, is redoubled by an experience of the experience. This gives the body's movements a kind of depth that stays with it across all its transitions-accumulating in memory, in habit, in reflex, in desire, in tendency. (2015:4)

[Feld]: Acoustemology conjoins "acoustics" and "epistemology" to theorize sound as a way of knowing. Acoustemology joins acoustics to epistemology to investigate sounding and listening as a knowing-in-action: a knowing-with and knowing through the audible.

(2015: 12) 
[Oliveros]: Deep Listening for me is learning to expand the perception of sounds to include the whole space/time continuum of sound-encountering the vastness and complexities as much as possible. Simultaneously, one ought to be able to target a sound or sequence of sounds as a focus within the space/time continuum and to perceive the detail or trajectory of the sound or sequence of sounds. Such focus should always return to, or be within the whole of the space/time continuum. (2005: 14)

[Feld]: Knowing through relations insists that one does not simply "acquire" knowledge but, rather, that one knows through an ongoing cumulative and interactive process of participation and reflection. (2015: 13)

[Massumi]: always entirely embodied, never entirely personal; it's never all contained in our emotions and conscious thoughts." "In affect, we are never alone. (2015: 6)

[Oliveros]: Sounds carry intelligence. Ideas, feelings and memories are triggered by sounds. If you are too narrow in your awareness of sounds, you are likely to be disconnected from your environment. (2005: 16)

[Stewart]: The ordinary is a circuit that's always tuned into some little something somewhere. A mode of attending to the possible and the threatening, it amasses the resonance in things. It flows through clichés of the self, agency, home, a life. (2007: 12)

[Stewart]: Rooted not in fixed conditions of possibility but in the actual lines of potential that a something coming together calls to mind and sets in motion. (2007: 2)

[Feld]: Given this transformative potency, it is not surprising that [...] sounds are understood not just as audible communications that tell time, season, environmental conditions, forest height and depth but also as communications from dead to living, as materializations reflecting absence in and through reverberation. [...] sounds are the voice of memory and the resonance of ancestry. (2015: 16)

[Oliveros]: Inclusive listening then opens us to all possibilities in the space/time continuum. Depending on our perspective or emotional arousal, or commitment to a goal or goals, we can enter the profound interplay of the universe through sounds. There may be a surprisingly strong relationship between the inner and outer experience of inclusive listening. Recording the flow of sounds through the space/time continuum like a journalist can promote a deeper understanding of your presence and meaning in the environment. There is always information in any sound that you perceive. (2005: 29)

[Stewart]: Ways of knowing become habitual at the drop of a hat. But it's ordinary affects that give things the quality of a something to inhabit and animate (15)." "There's a politics to being/feeling connected (or not), to impacts that are shared (or not), to energies spent worrying or scheming (or not), to affective contagion, and to all the forms of attunement and attachment (2007: 16).

[Massumi]: Affective doubling gives the body's movements a kind of depth that stays with it across all its transitions-accumulating in memory, in habit, in reflex, in desire, in tendency.

[Feld]: Acoustemology figures in stories of sounding as heterogeneous contingent relating; stories of sounding as cohabiting; stories where sound figures the ground of difference-radical or otherwise-and what it means to attend and attune; to live with listening to that. (2015: 15)

[Massumi]: [Sound and the sounding body's] capacity for affecting or being affected are not two different capacities-they always go together. When you affect something, you are at the same time opening yourself up to being affected in turn, and in a slightly different way than you might have been the moment before. You have made a transition, however slight. You have stepped over a threshold. Affect is this passing of a threshold, seen from the point of view of the change in capacity. (2015: 4)

This dialogue situates sound and sounding as relational, in connection with some-body, draws our focus to attuning our bodies to other bodies, hu- 
man and more-than-human, through sound and the affective capacity of sound and sounding and listening bodies. It promotes sounded thinking as a form of transindividual solidarity in relation to one another by carrying the potential to affect and to be affected, that transgresses bodies, consciousness and categories to always be in motion. In such a thinking through relations in sound, a sense of connectedness to other bodies appears both as "trans-action" and "inter-action" Dewey 1960 as cited in Feld (2015: 13) emphasizing the between-ness and across-ness of thoughts, bodies and affects in sound and through a sounded thinking.

\section{Theme 1 - An exchange about memory}

Famarin: In SJ recorded on July 1st, 7:30 pm, sitting at the bluffs with the sounds of the water:

As I am observing how the waves crash through the shores, the pushing and pulling of waves to the shores, it [has] kick-started the idea of the present moment, that being in the moment through sound and movement of the waves. As COVID-19 restrictions are now changing at some places, it signals to me that we have to focus on the present moment. This [sound and movement] is all very cyclical.

Joshi: In SJ recorded on June 23rd, 9:03 pm, walking around a college and residence building at her University:

Through this all, something that is constant, that is unchanged is our dependence on technology. These sonic bursts in terms of machines that regulate electricity, the heating and cooling systems, that I can hear as I walk past these empty buildings, permeate a particular kind of nostalgia that comes out of the pandemic. I am reminded of how I would not be able to hear these machinic sounds if these buildings were inhabited by humans.

[...]. So, this thinking of memories, that is generated by the pandemic sounds (let's call it that), then brings me to a realization that the sounds of the present remind us of the sounds of the past-even those we didn't experience in the past...?!

Famarin: In SJ, recorded on June 27th; 11:10 pm, standing on the balcony, responding to the rain and the petrichor:

I think there is a recurring theme about me, sound and remembering about the things in the past! It seems like, through certain sounds, and the ways my body sounds with those sounds, I'm almost transported back to the exact place where I grew up. So right now, as I record this, the sound of the rain is nostalgic, my body is turning to the rain and I am being a child again!

Joshi: In SJ recorded on June 23rd, 9:10 pm, walking around her University, surrounded by patches of grass and some wildlife:

Do sounds have history then, or do they evoke history by reminding us of our memories? I have started thinking about what a history of sound would look like? Would it be one [history], it wouldn't be one. Perhaps we can think of a certain sound as an event, a thing that rises and something that ends. That there is no history to it, because it keeps coming back and it keeps emerging, in and out, up and down.

What have we come to know by un-assuming a certain form or idea of knowledge? What sounded thinking can do and what does a sounded thinking make apparent? 
Our contemplations about memory do not make our instantaneously felt memories, or memories that live within us for long, useful for and through nostalgia. Rather, we try to question the historicization of sounds, memories, and sounds that evoke memories that necessitate the usage of memory and nostalgia to produce something better and improved. For us, the sounds of the machines, empty buildings, rain, point to a certain rest in history-a pause, from where history can begin again, a point at which history does not totalize and neglect other histories, where history does not remain historic at all. By thinking of memories and history in terms of sound, history becomes a coming together of events as they are, fleeting, ever changing, always in motion (de La Cadena 2015). A sounded thinking tries to destabilize history.

\section{Theme 2 - An exchange about incipient thoughts, desires and the recognition of the unknown}

Joshi: In SJ recorded on July 14 th, 8:24 pm, is sitting on a parapet, covered by trees, and surrounded by 7 kids and their families:

A thinking and a knowing has come to me, while I was listening to the Pakistani Band, Strings! I have recognized that their music moves me to a transcendental, external place, and an immanent internal place. It moves me so greatly, I tear up, not with joy or sorrow-just tear up! It penetrates and permeates, just like the cries of a child, as she cries as I record.

Famarin: In SJ recorded on July 2nd, 7:10 pm, pondering with a journal on the balcony:

As I was re-reading my past journal entries that I wrote as a new immigrant to Canada, I could hear myself, telling my interior self as to how I should act and what I should do. This being able to hear has given rise to lots of thoughts, questions and ideas.

It is an unknown, but familiar reverberation of my other [old] self, telling my current self something. I think I feel or recognize a sense of belonging in this reverberation. Now, I've had the desire to think with and think by the means of sound, not about sound. I am [being] with [my own] sound.

Joshi: In SJ recorded on July 14 th, 8:31 pm, is sitting on a parapet, covered by trees, and surrounded by 7 kids and their families:

Their music, as a form of sound and language has connected me to a sort of knowing that is happening/happened within, an interior knowing. Greatly profound. This knowing by being moved is a bodily and felt experience, and I think sound has done that.

All of this has given rise to an incipient desire, a desire that gives me so much strength as it completely engulfs me. A desire so strong, so moving that it transpires through everything and nothing. I know it is something, but I don't know what it is yet... it has a power to draw me towards it, and yet it is unknown. Maybe sound can help in this realizing of the desire!

Famarin: In SJ recorded on July $6 \mathrm{th}, 12: 10 \mathrm{pm}$, is sitting in front of a film printing store surrounded by condominiums, waiting for work to start.

I have had a very confused, somewhat painful confrontation with sound and through sound. I was with my friends from the Philippines. We were talking about how we have a 
third place of belonging, but things happening at home [politically still affect us]. Why? There is a lot going on back home, the people here and there must speak, but, how can we amplify our voices here when they are suppressed at home?

Home for me is in many places; it is a good thing, yet the sounds of the Philippines and here incite a sense of vagueness; a blurry remembrance of what it is to belong somewhere? Why do we have the desire to belong? How can we connect and belong through sound?

What have we come to know by un-assuming a certain form or idea of knowledge? What sounded thinking can do and what does a sounded thinking make apparent?

We rethink our understanding of desire, desires that are felt but not yet palpable. We call them incipient desires. We recognize the presence of these desires throughout our practice of sound journaling. An incipient desire is a desire that is forming and is always in motion. It vibrates and oscillates. It can only be recognized by a body that is attuned to sounds because it is fleeting and vibrational, it transgresses fixity and categories. Incipient thoughts and desires do not assume, they speculate. Incipient desires differentiate themselves from desires by mirroring the properties of sound. They are vibrational and emerge from collision and chaos. Such desires (re) connect us with other bodies while destabilizing our thinking and knowing bodies. These desires have the potentialities to provoke a coming together beyond recognized forms of political thinking and action. They permeate and contaminate bodies to create transindividual solidarities. They mirror the viral, the insurgent. We also differentiate recognition and knowing in the dialogue that follows. We suggest that moving past the strictures of knowledge can happen by recognizing the potentialities of lurking thoughts and desires in our everyday life. And that for us happens through a sounded thinking.

\section{Theme 3 - An exchange about existence, relation and being with the world}

Joshi: In SJ recorded on July 1st, 10:02 pm, is walking home from a picnic

"What does it mean to be with? Be with ourselves, other bodies, human and non-human and thus, the world? What if we involve ourselves in the lives of other sounding bodies, by attuning ourselves to/through sensation?

Famarin: In SJ recorded on July 2 nd, 7:10 pm, pondering with a journal on the balcony

As I rethink through my journal of the past, while journaling [with sound] in the present, I can feel this interconnectedness of my thoughts, my being, as a tentacularity of a certain sounded relationality, as a series of interlaced trails. The past journal entries have an unexplored connection and unexpected harmony with my present self.

Joshi: In SJ recorded on July 1st; 10:02 pm, is walking home from a picnic 
As I walk, and come across the bugs, the dog [I am so scared of dogs], and partially crush a worm, I am thinking... that the bugs, the dog, and the worms all remind me of my humanistic existence, one with the beyond human, and one with what is inanimate, but is still a sounding body.

Can sound then help us extend the idea of an involution? A rolling inwards, instead of a moving forward when thinking of our relationship with the world? If everything sounds, how do we attune ourselves so that we can listen to everything that does not emanate a sense of sound in the same way that we are so used to sensing and hearing?

Famarin: In SJ recorded on June 23rd, 12:10 am, In the subway, going home from work

As I record the sound journal on my way back home on the train, I sense a taking over happening. The sounds of the train rushing through the tunnel, the sound of tiredness, and that of the end of the day are taking over my body, my thoughts, as I speak. The feltness of it is comforting and indescribable. I am slowly becoming one with the sounds that surround me, and the sounds that are in me. Like a relationality with the past, the present, and what is yet to come.

What have we come to know by un-assuming a certain form or idea of knowledge? What sounded thinking can do and what does a sounded thinking make apparent?

We ask what it can mean to be with the world and one another? How can we be with something or someone? We imagine a life-world where affective relations between bodies are more than a series of economic encounters guided by the militarized logic of the neoliberal state. We turn inwards to our sensations and learn that [we as] sounding bodies always collide. That collision is generative as we can find interconnectedness in it. In such collisions, we find the energies to become viral and exist not in isolation, but in an ecology where we absorb, penetrate other bodies and irrupt from other bodies (Manning \& Massumi 2014). Through sounded thinking we learn that we can navigate, think and reside in collisions, and paying attention to these collisions can further allow us to unfold permeating affective ecologies that promote transindividual solidarity.

\section{Theme 4 - An exchange on intuitive noticing:}

Joshi: In SJ recorded on June 30th, 10:30 pm, is sitting at a bench near the New Student Centre at her University:

The Moon is so beautiful. I can't hear it, but I do sense the moon-ness of it. I don't know what that can be! How do we notice what we often leave unnoticed? Similar to how I was posing questions about our capacity to hear bodies that don't emit sounds as we can hear, how do we notice against what we are taught to notice and un-notice? Noticing and relaying thoughts goes hand in hand. We relay our thoughts, experiences, and feelings through words by the means of language, but we also express through sensations and actions! How do we notice differently if language and the visual is not enough?

Famarin: In SJ recorded on June 30th, 9 pm, taking a short walk around the neighborhood: 
Sometimes, I perceive. I trust my perception of people, things, and surroundings. In that perception, sound has emerged as mediation. It mediates thoughts, ideas, even spirituality. Like, the ways of the sound make spirituality tangible, palpable almost.

My body perceives and mediates, too. It is as if my body is acting out something for me, without me trying to. But I'm confused if it is my brain consciously or unconsciously thinking about 'something' or if it is my body? For instance, I have heard my heart sink to the very bottom of my core. It's as if it's pulling me down and I'm no longer in control of myself.

Joshi: In SJ recorded on July 1st, 10:02 pm, is walking home from a picnic:

So, in a direct response to your sound journal, we can say then that the body is always living in sound and the body itself sounds. Then, how do we notice these sensations, and our flesh expanding or constricting? How do we notice what's happening inwards, what is precognitive, what is perceived and felt but not yet thought of? I think, that such a noticing, which is intuitive in the sense that we are sensing and perceiving the moving body, the body that is in constant motion, because it is a sounding body, can happen through an understanding of the difference between knowledge (gained through noticing) and recognition that happens through intuitive noticing. Maybe then, recognition is an active knowing, a knowing that is always in motion. It happens through incipient desires, thoughts and the soundings of them. Whereas, knowledge as we know it, and know of it, is a passive knowing, something that sits, something that is rigid and complacent.

I am drawn to movement, and I want to dance all of these new knowings!

Famarin: In SJ recorded on June 25th, 9:15pm, walking around the neighborhood, observing brick houses and the stillness inside:

This is a nice practice! As I go about telling you about my day on the phone, I get to revisit what I was thinking at the moment, how I was thinking, and what was my body doing as the thinking was happening? Often, it has felt like a pouring of water out of something, but at the same time, into something. Only here, I am pouring thoughts, ideas and feelings out but as I pour and surrender, I'm able to go back to myself, noticing myself! I wish I could dance this out right now!

What have we come to know by un-assuming a certain form or idea of knowledge? What sounded thinking can do and what does a sounded thinking make apparent?

As we try to grasp the unquantifiable within us and the without that is suspended in the atmosphere, we learn to move beyond merely hearing, seeing, and feeling what is predominant. We turn to Bergson's sense of intuition where one perceives the moving senses, the anticipation of the body, the constricting veins, the gushing blood (2007), and attune with what surrounds us through the sounds inside us. As we notice through intuition, we recognize that the unquantifiable within is ungraspable. We suggest that an intuitive noticing happens through our sounding and listening bodies rather than just our knowing mind. Through an intuitive noticing, we recognize intensities, potentialities and ruptures that are disregarded or missed when just noticing. Such a noticing goes against normative logic. A sounded thinking is necessary for an intuitive noticing, as it moves us beyond the human made noises and 
logics to reach for voices within and beyond us. Intuitive noticing then emerges from chaos and depends upon the relationality of our bodies.

A sounded thinking as we have suggested is thus a thinking against binding categories. It privileges speculations over assumptions and becomes a tendency whereby one comes to know by attending to the complexity of our perceptive experience in relation to other bodies over fixed knowledge. A sounded thinking reconsiders knowledge and promotes a coming-together in collision towards an ecology that refutes fixity and categorizations. In the next section, we try to perform this sounded thinking.

\section{Sounded improv: a bodily poetics in motion ${ }^{7}$}

As dancers, as individuals who like to move, we started noticing throughout the sound journaling that our responses to each other's reflections, thoughts, ideas were very bodily. Sound, as human and non-human voices, background noises, or as interior feelings, provoked a somatic exploration of sounding and listening. Such an exploration further helped us comprehend the sonic sensibilities of all bodies that account for transformations across space, time, and scale. We heard, saw, and felt the presence of our bodies in the ways we understood each others' sounding and listening practices. These bodily responses were varied, but constant. Our responses pointed to an immediate and strong desire to move; to dance to the voices of the other and the vibrations that surround us. Hence, at the end of the practice, when we started conceiving ideas for this dossier, it was apparent that we keep our sounding and listening bodies visible by implicating them in a sound-movement practice.

We chose to be surrounded by trees, with rustling sounds of branches and twittering birds. We wanted to explore how the body responds and attends to the nonliving and nonhuman as it cohabits at the centre of the green canopy. Far from the urban, we found our bodies attuning to the sound of our surroundings. Matching with the flute cover of 'The Wind Stories' by Varun Kumar, the music provided a mapping of the sounds of the organic: the breeze, the soft crunch of twigs, the scurrying of animals around. As we let ourselves be, we allowed our bodies to listen and sound in movement. The performance is unchoreographed and unrehearsed because we wanted to keep it as instantaneous as possible. We respond to the music, to the presence of each other, and our friend who kindly agreed to film our dance. We responded to the unsaid but anticipated fear of not social distancing while we

$7 \quad$ Contact Improvisation, a form of dance brought forward by Steve Paxton in the 1970s, inspires our Sounded Improv. The form is about undirected, unchoreographed movements that focus on tuning to oneself and responding to your partner's movement. We coined the term 'Sounded Improv' as instead of focusing on points of body contact to interpret the felt, we attune ourselves to sound and how sound could lead our body movements (http://www. foundsf.org/index.php?title=The_Experiment_Called_Contact_Improvisation). 
were dancing. Our rawness and ad hoc movements were an attempt to point to the idea that sounds emerge and submerge when bodies collide, meet and coalesce. We let one another affect and be affected by each of our presence. We let the rhythmic and bodily culmination inspire our moves.

Technically, we are both trained in different dance forms. SB2 is trained in Hip Hop/ Krump, which is powerful and emotive. SB1 learns Kathak, an Indian classical dance form, which has a certain fixity to it. It was not our attempt to divulge from our dance techniques. Even when our bodies were guided just by sounds, we remained with our technique, but we spontaneously created movement. A sense of involuntariness, something guiding our dance, that is not our training, choreography, and practice, is very visible in the performance.

We learnt that through our movement practices, we materialized, felt, and understood sounds. We draw from contact improv, but we give more importance to listening to the sounds that surround us, rather than letting our movements be guided by touch. And as sounds, both internal and external became our point of contact, rather than touch itself, we call this practice Sounded Improv. Our bodies in this performance relay the affectivity and hapticality of sound. They relay a thinking-in-movement that cuts distance between all bodies. They relay a knowing that happens through sound and bodies, perhaps through sounding bodies - a knowledge that emerges as we immerse ourselves in the sensoriality of sound and experience. They relay a knowledge that is not bound by the idea of knowledge itself.

We cling to the incipient, the inflection of sound; the immeasurability and indelibility of it. We try to grasp the thoughts and vibrations through the gyration of the body, through the thrush and pull of the incoming, of the unknown. It is like how your body jumps at the sound of your favourite song on the radio, the ice cream truck in the distance, the screeching of cars and the cry of the child. It is beyond words. These are unregulated rhythms that can only be sensed; and even before that, felt. We hope that as we attempt to materialize the inchoate; we bring to light the fleeting yet intense sensorial sound experience of the sounding body - a body that transforms, but is not regulated. This is made apparent when we started recording the narration that is added to the performance. We sat with our backs touching the other, feeling the other person breathe, feeling their lungs and diaphragm, their inhales and exhales to be in complete sync to record the text. As we touch each other through sound and the unregulated body, we experience that, "the body begins with sound, in sound. The sound of the body is the sound of the other, but it is also the sound of the same. We resound together" Kapchan (2015:33).

As we collectively emerge from sound, we are made one, yet exist variously in a symbiosis of sounds that Julia Kristeva calls the "Chora, a space of continuity where sound, shapes, sensations do not belong to anyone, they simply are" Kristeva 1982, 1984 as cited in Kapchan (2015:34), we feel in our bodies, a breaking free from becoming something. The dance/movement 
practice and our sound journaling depict sounded forms of solidarity and being together, not only with humans, but beyond humans and the material, in times of uncertain futures. ${ }^{8}$

\section{Speculative endings, endings that speculate}

The project has probed us to pay renewed attention to the acoustics, rhythms and vibrations around us. As we suggest through the paper, to do a sounded thinking is to attend to sounds and to attend with sounds, to ourselves, others and our surroundings in opposition to a regulated thinking. Such attention to sounds through a sounded thinking can help us tap into the hapticality of being, thinking and feeling in relation, and also into the viral intertwinings of our existence with humans and more-than-humans. We have turned to and stayed with speculations about the process, what emerges from it, what we might make of it, such that there is no definitive purpose of our practice and our writing. As this is a collaborative project, we focus on relationality with ourselves, each other, the human, nonhuman and nonliving. This project was a heuristic inquiry, a conversation with one another and with what is around us. Sound journaling during COVID-19 taught us how to turn to the sound of our bodies when the usual pace of life and the certainty were taken away. In listening deeply to our bodies and other sounding bodies, we notice how bodies remember and respond to desires, memories, nostalgia, and predominant knowings of the world through sound. We could listen to the moon by intuitively noticing through sounds. We could transgress categorizations and the urgency to become something by learning to be with sounds. We turned inwards to sensation and to the body through sound, both outside and within us, to sound ourselves out of our definitive frameworks, that limit and territorialize thought and knowledge. We tried to break free from the dualism of the mind and body through this sounded method. The sounded thinking and the method proposed here do not regulate, they let you be viral, hence; we let ourselves be as we write this paper, where we release the need to become something-immigrants, researchers, women, artists, and just be with the world. We hope that our affective approach to sound would inspire readers to pay attention to the potentialities of the unseen and the indelible that knowings and knowledge can take any shape or form and do not have to conform to the normative forms of what knowledge should be like.

Through speculations, and with speculations we find ourselves immersed in this practice that helped surface, and sometimes birth ideas, knowings, and experiences in the last few months. We wish to leave you, the reader, the listener, and the producer of sounds with our speculations and ideas that will help you (hopefully) speculate your own speculations, your incipient desires, your sounded knowledges. Our goal from the practice and the inquiry was to create a tangible way to attune ourselves to sound, to sense the unseen and

8 Performance link: https://vimeo.com/443242685 (password: Beingviral) 
the undeterminable in order to understand how bodies negotiate and resonate with the forces and categorizations that create a sense of otherness. And with that we hope you will use this practice, remold it, and make it your own to be with the world through a sounded thinking!

\section{References}

Blackman, Lisa. 2012. Immaterial Bodies: Affect, Embodiment, Mediation. London: Sage.

Bergson, Henri. 2007. Matter and Memory. New York: Cosimo Books.

De la Cadena, Marisol. 2015. Earth Beings: Ecologies of Practice Across Andean Worlds. Durham, NC: Duke University Press.

Feld, Steven. 2015. "Acoustemology". PP 12-21 in Keywords in Sound, edited by Sakakeeny,Matt. Durham: Duke University Press Books.

Harney, Stefano and Fred Moten. 2013. The Undercommons: Fugitive Planning and BlackStudy.

New York: NY, Minor Compositions.

Kapchan, Deborah. 2015. "Body". PP 33-44 in Keywords in Sound, edited by

Sakakeeny Matt. Durham: Duke University Press Books.

Kristeva, Julia. 1982. Powers of Horror: An Essay on Abjection, translated by Leon Roudiez.

New York: Columbia University Press.

Kristeva, Julia. 1984. Revolution in Poetic Language, translated by Margaret Walker. NewYork:

Columbia University Press.

Manning, Erin, and Brian Massumi. 2014. Thought in the Act: Passages in the Ecology of Experience. University of Minnesota Press.

Massumi, Brian. 2015. The Politics of Affect. Cambridge: Polity.

Nelson, Robin. 2015. In Practice as Research in the Arts. London: Palgrave Macmillan UK.

Oliveros, Pauline. 2005. Deep Listening: A Composer's Sound Practice. iUniverse, Inc.

Oliveros, Pauline. 2008. "Deep Listening-The Center For Deep Listening.". https://www. deeplistening.rpi.edu/deep-listening/.

Paiva, D., Cachinho, H. \& 12 Anonymous Participants (2018). "The first impression in the urban sonic experience: transitions, attention, and attunement." Geografiska Annaler: Series B, Human Geography, 100 (4), 329-342.

Puar, Jasbir. 2013. "Homonationalism as assemblage: Viral travels, affective sexualities." Jindal Global Law Review 4 (2): 23-43.

Stewart, Kathleen. 2007. Ordinary Affects. Durham: Duke University Press.

Varun Kumar. "Kal Ho Naa Ho - Title Track Flute cover, The Wind Stories". Youtube video, 3:09 October 20, 2017. https://www.youtube.com/watch?v=Y6RzPqoEEJM

Date received: 2020-08-01

Date accepted: 2021-06-02 